\title{
Luomukasvustosta valmistettu vehnä-rehuvirnasäilörehu teuraaksi kasva- tettavien hereford-hiehojen vieroituksen jälkeisessä ruokinnassa
}

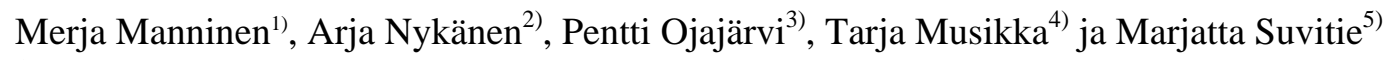 \\ ${ }^{1)}$ MTT, 31600 Jokioinen, merja.manninen@mtt.fi \\ ${ }^{2)}$ MTT, 51900 Juva, arja.nykanen@mtt.fi \\ ${ }^{3)}$ Pohjois-Karjalan ammattikorkeakoulu, 82430 Puhos, pentti.ojajarvi@ncp.fi \\ ${ }^{4)}$ Keski-Karjalan kehittämis- ja tietokeskus KETI, 82430 Puhos, tarja.musikka@pp.inet.fi \\ ${ }^{5)}$ MTT, 71750 Maaninka, marjatta.suvitie@mtt.fi
}

\section{Tiivistelmä}

Virnoja viljellään seoksena viljojen kanssa, koska virna vähentää kasvuston typpilannoitustarvetta ja lisää säilörehun valkuaispitoisuutta. Rehu- ja ruisvirnan viljely on yleistä luonnonmukaisessa tuotannossa ja sen käyttö on lisääntynyt luonnonmukaisen tuotannon lisääntyessä. Tämä tutkimus selvitti luonnonmukaisesti viljellyn vehnä-rehuvirnakokoviljasäilörehun (VVSR) tuotantovaikutuksen joko sellaisenaan tai luomukauralla täydennettynä hereford (hf)-hiehojen kasvuun sekä ruhon ja lihan laatuun. Vertailurehuna oli heinäksi tehdyn, apilapitoisen luomunurmen odelmasta valmistettu nurmisäilörehu (NSR).

Kokeeseen otettiin 20 hf-lehmävasikkaa, jotka kokeen alkaessa painoivat keskimäärin 252 kg. Koe tehtiin Kiteen oppimiskeskuksen navetassa. VVSR-kasvusto niitettiin niittomurskaimella ja pyöröpaalattiin/muovitettiin. NSR-kasvusto niitettiin niittomurskaimella, paalattiin silppuavalla pyöröpaalaimella ja muovitettiin. Säilöntään käytettiin AIV 2 Plus-liuosta. Väkirehuna oli luomukaura. Hiehoille annettiin kivennäis- ja vitamiinitäydennys. Hiehot saivat vapaasti säilörehua ja puolet kummankin karkearehun eläimistä kauraa 2,0 kg KA/pv 310 elopainokiloon asti ja sen jälkeen 1,0 kg KA/pv teurastukseen. Teuraspainotavoite oli $180 \mathrm{~kg}$. Hiehot teurastettiin Kiteen opetusteurastamossa.

VVSR:n kuiva-ainesato oli $4100 \mathrm{~kg} / \mathrm{ha}$. Rehuvirnan osuus kasvustossa oli ennen korjuuta otetuissa näytteissä 35 \% ja vehnän 31 \% KA:sta. Peltovalvattia esiintyi paikoin runsaasti. NSR:n kuivaainesato oli $2530 \mathrm{~kg} / \mathrm{ha}$. Rehun Ca-pitoisuuden perusteella rehun apilapitoisuus oli noin $50 \%$. VVSR:n KA-pitoisuus oli keskimäärin 356 g/kg ja D-arvo 59,9 \%. KA-kilo sisälsi 0,81 RY, 152 g raakavalkuaista ja 79 g OIV. NSR:n vastaavat arvot olivat 387 g/kg, 66,9 \%, 0,92 RY, 143 g ja 81 g. Rehut säilyivät paaleissa hyvin. Väkirehu vähensi hiehojen karkearehun syöntiä huomattavasti. Kokonaiskuiva-aineen syönti oli keskimäärin 5,8 kg. Energian saanti muodostui väkirehulisällä suuremmaksi kuin pelkällä karkearehuruokinnalla (5,3 vs. 4,7 RY). Väkirehulisä lyhensi hiehojen kasvatuskautta kuudella viikolla. Tavoiteteuraspaino saavutettiin lukuun ottamatta ilman väkirehulisää olleita VVSR-hiehoja. NSR-hiehojen kasvu oli keskimäärin 112 g/pv parempaa kuin VVSR-hiehojen. Väkirehu tehosti hiehojen kasvua $224 \mathrm{~g} / \mathrm{pv}$ ilman väkirehua olleisiin hiehoihin verrattuna. NSR-hiehot rasvoittuivat VVSR-hiehoja runsaammin. Väkirehulisä paransi VVSR-hiehojen lihan mureutta, mutta NSR-ruokinnalla vaikutus oli lievästi päinvastainen. Ruhojen tervaliha-\% oli 0.

VVSR osoittautui kokeessa nurmisäilörehua heikommaksi karkearehuksi. Suurin syy tähän lienee ollut VVSR:n huono sulavuus. Hiehojen kasvu VVSR:lla ilman väkirehua jäi heikoksi ollen keskimäärin vain 515 g/pv. Väkirehu tehosti hiehojen kasvua huomattavasti. Ruokintojen vaikutus lihan syöntilaatuun oli marginaalinen. Virnan siemenmäärän lisääminen kylvöseokseen tai muu korjuuaika olisi mahdollisesti parantanut rehun sulavuutta.

Asiasanat: hieho, luonnonmukainen tuotanto, naudanlihantuotanto, rehuvirna, ruokinta 


\section{Johdanto}

Virnoja viljellään viljojen kanssa seoksina, koska virna typpeä sitovana palkokasvina vähentää kasvuston typpilannoitustarvetta ja lisää myös säilörehun raakavalkuaispitoisuutta (Lehto ja Joki-Tokola 1999a ja 1999b, Joki-Tokola ym. 2002). Rehuvirnan (Vicia sativa L.) ja ruisvirnan (Vicia arvensis L.) viljely on yleistä luonnonmukaisessa tuotannossa ja sen käyttö on lisääntynyt luonnonmukaisen tuotannon lisääntyessä. Seosviljelystä on etua luonnonmukaisessa tuotannossa, jossa typpi usein muodostuu satoa rajoittavaksi tekijäksi. Seoskasvustosta voidaan korjata kesän aikana 1-2 säilörehusatoa, jolloin rehun raakavalkuaispitoisuus ja sulavuus lisääntyvät korjuukertojen lisääntyessä. Yhden korjuukerran etuna on kuitenkin korjuukustannusten väheneminen. Seoskasvuston yhdestä korjuukerrasta on uudelle nurmelle myös vähemmän haittaa kuin kahdesta korjuukerrasta, jos seoskasvustoa käytetään perustettavan nurmen suojakasvina. Hereford (hf)-sonneilla tehdyssä kokeessa rehuvirna paransi hieman ohrakokoviljasäilörehun tuotantovaikutuksia (Joki-Tokola ym. 2002). Vehnä tuottaa hyvän, sulavuudeltaan ja maittavuudeltaan paremman sadon kuin kaura ja lujakortisena tukee virnakasvustoa.

Ennen tässä selvitettävää tutkimusta MTT on tutkinut teurashiehojen ruokintaa viidessä kokeessa yhteistyössä Pohjois-Karjalan ammattikorkeakoulun ja Kiteen oppimiskeskuksen kanssa (Rinne ym. 1998, Rinne ja Ojajärvi 1998, Manninen ja Ojajärvi 2000, Manninen ym. 2002, Manninen ym. 2004). Viimeisimmässä kokeessa tutkittiin kaura-rehuvirnaseoskasvuston tuotantovaikutus lihahiehon kasvatuksessa ja vertailurehuna oli tavanomaisella tuotantotavalla heinän odelmasta valmistettu nurmisäilörehu. Hiehot ruokittiin vapaasti mainituilla rehuilla ja teurastettiin 13 kk:n iässä. Rehuvirna varjosti kasvukauden loppuvaiheessa huomattavasti kauraa. Luomukasvustosta valmistettu kaurarehuvirnasäilörehu osoittautui heinän odelmasta valmistetun nurmisäilörehun veroiseksi rehuksi lihahiehojen ruokinnassa. Hiehojen kasvu oli keskimäärin vain 604 g päivässä, mitä voidaan pitää teuraaksi kasvatettaville hiehoille heikkona.

Tämä tutkimus selvitti luomukasvustosta valmistetun vehnä-rehuvirnakokoviljasäilörehun tuotantovaikutuksen sellaisenaan tai luomukauralla täydennettynä hereford-hiehojen kasvuun sekä ruhon ja lihan laatuun. Vertailurehuna oli luomukasvustosta valmistettu apilapitoinen nurmisäilörehu. Hiehot saivat säilörehua vapaasti ja puolet kummankin karkearehutyypin eläimistä saivat kauraa alenevasti 2,0-1,0 kg kuiva-ainetta päivässä ennen teurastusta.

\section{Aineisto ja menetelmät}

\section{Eläinaines ja tuotanto-olosuhteet}

Kokeeseen otettiin 20 MTT:n emolehmänavetalla 13.3.-12.4.2002 syntynyttä hf-lehmävasikkaa. Vasikoiden isinä olivat hf-sonnit Koskis Noak (12) ja Innilän Leevi (8). Ennen koetta vasikat olivat emiensä kanssa laitumella eivätkä saaneet siellä väkirehua. Vasikat vieroitettiin 27.9.2002 252 kiloisina kasvun oltua ennen vieroitusta keskimäärin 1172 g päivässä. Kokeen alkaessa 29.10.2002 vasikat olivat keskimäärin 214 (SD 7,1) päivän ikäisiä ja painoivat 252 kiloa (SD 16,2). Koe tehtiin Kiteen oppimiskeskuksen navetan yksilöruokintaparsissa. Eläimet punnittiin ja kuntoluokitettiin (Lowman ym. 1976) säännöllisesti.

\section{Rehut ja ruokinta}

Rehuina olivat luomukasvustosta tehty vehnä-rehuvirnasäilörehu (VVSR) ja heinäksi tehdyn luomunurmen odelmasta valmistettu apilapitoinen nurmisäilörehu (NSR). Vehnän (Manu) ja rehuvirnan (Ebena) siemenseos (98 ja 31 kg/ha) kylvettiin 13.5.2002 nurmen (timotei-nurminata-puna-apila) suojakasvustoksi, nurmen siementä käytettiin 12-6-4 kg/ha. Maalajina oli multava, hieno hieta. Lannoitukseen käytettiin naudan kuivikelantaa ja sian lietelantaa kumpaakin $20 \mathrm{~m}^{3} / \mathrm{ha}$. Seosrehukasvusto niitettiin 3.8.2002 niittomurskaimella ja pyöröpaalattiin/muovitettiin seuraavana päivänä. Nurmisäilörehun kasvusto oli toisen vuoden apilapitoinen nurmi (timotei $35 \%$ - nurminata $20 \%$ - apila $45 \%$ kylvöseoksesta), jonka lannoitukseen käytettiin naudan virtsaa 20 t/ha ensimmäisen sadonkorjuun jälkeen. Nurmisäilörehukasvusto niitettiin 23.8.2002 niittomurskaimella ja paalattiin silppuavalla pyöröpaalaimella ja muovitettiin seuraavana päivänä. Molempien rehujen säilöntään käytettiin AIV 2 Plus liuosta (760 g muurahaishappoa/kg ja $55 \mathrm{~g}$ ammoniumformiaatti/kg). Väkirehuna oli luomukaura, jonka lannoitukseen käytettiin naudan kuivikelantaa $20 \mathrm{~m}^{3} /$ ha. Kivennäisenä käytettiin Luonnon FosforiMineraa (Suomen Rehu Oy; Ca 47, P 53, Na 55 ja Mg 70 g/kg) ja vitamiinina Mestarin ADEvitamiiniseosta (Valmistuttaja K-maatalous; A 2000000 ky/kg, D 200000 ky/kg, E 2000 mg/kg, 
Niasiini 2000 mg/kg, B $121 \mathrm{mg} / \mathrm{kg}$, Natriumseleniittiä 22,2 mg/kg). Hiehot saivat vapaasti säilörehua ja puolet kummankin karkearehutyypin eläimistä kauraa 2,0 kg KA/pv 310 elopainokiloon asti ja sen jälkeen $1,0 \mathrm{~kg} \mathrm{KA} / \mathrm{pv}$ teurastukseen. Hiehojen teuraspainotavoite oli $180 \mathrm{~kg}$. Vettä eläimet saivat vapaasti.

Säilörehuista analysoitiin MTT:llä kuiva-aine (KA), tuhka, kivennäiset (Ca, Mg, P, K, Na, Fe, $\mathrm{Cu}, \mathrm{Zn}, \mathrm{Mn}$ ), raakaproteiini, ND-kuitu (Van Soest ym. 1991), orgaanisen aineen in vitrosellulaasisulavuus (Friedel 1990) ja seossäilörehusta tärkkelys (McCleary ym. 1994). Kokoviljaseossäilörehun energia-, OIV- ja PVT-pitoisuus laskettiin huomioimalla kasvustonäytteestä botaanisen analyysin perusteella saatu kasvuston kasvilajikoostumus korjuuhetkellä. Väkirehun rehuarvo laskettiin kemiallisen koostumuksen perusteella (Tuori ym. 2002).

\section{Teurastus, ruhon ja lihan laatu}

Hiehot teurastettiin Kiteen opetusteurastamossa. Ruhot luokitettiin EUROP-luokituksen mukaisesti. Ulkofileestä määritettiin loppu-pH 36-48 h teurastuksesta ja leikattiin pala, joka toimitettiin pakastamatta LTK:een aistinvaraiseen arvosteluun ja konsistenssimääritykseen. Näytteet arvioitiin aistinvaraisesti noin kahden viikon kuluttua Kiteellä tehdystä vakuumipakkauksesta, siihen asti niitä säilytettiin kylmiössä $+8^{\circ} \mathrm{C}\left( \pm 2^{\circ}\right)$. Konsistenssi määritettiin aistinvaraista arvostelua seuraavana päivänä.

\section{Tilastollinen käsittely}

Jokaisella käsittelyllä oli kolme Koskis Noakin ja kaksi Innilän Leevin tytärtä ja isän vaikutus huomioitiin mallissa. Käsittely-tekijät olivat faktoriaalisia eli muodostuivat kahden eri tekijän kombinaatioista (väkirehu ruokinnassa +/- ja karkearehutyyppi). Analyysit suoritettiin SAS:n (1999) versiolla 8.2. varianssianalyysilla (GLM) käyttäen mallia:

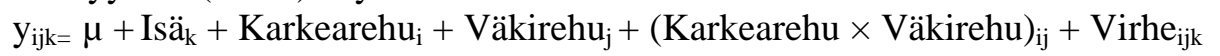

\section{Tulokset ja tulosten tarkastelu}

VVSR:n tuoresadoksi määritettiin 17700 kg/ha ja kuiva-ainesadoksi 4100 kg/ha. Rehuvirnan osuus kasvustosta otetuissa näytteissä oli ennen korjuuta 35 \% ja vehnän 31 \% KA:sta. Erityisesti peltovalvattia esiintyi paikoin runsaasti. Korjuuhetkellä vehnän D-arvo oli 52,2 \% ja raakavalkuaispitoisuus 106 g/kg KA. Vastaavasti rehuvirnan D-arvo oli 65,1 \% ja raakavalkuaispitoisuus 212 g/kg KA. Vehnä oli taikinatuleentumisasteella ja virnojen palot olivat kehittymässä, kukkia oli enää vähän näkyvissä. Nurmisäilörehun tuoresato oli 8000 kg/ha ja kuiva-ainesato 2530 kg/ha. Rehun Ca-pitoisuuden perusteella rehun apilapitoisuus on ollut noin 50 \%. Nurmisäilörehun D-arvo oli korjuuhetkellä 65,7 \% ja raakavalkuaispitoisuus 137 g/kg KA. Virnan kivennäiskoostumus on pääosin samaa suuruusluokkaa kuin nurmisäilörehun, ainoastaan natriumia on enemmän ja rautaa ja mangaania vähemmän (Taulukko 1). Vehnän kivennäispitoisuudet ovat pienempiä kaikkien analysoitujen kivennäisaineiden osalta. Vehnän tähkissä on korsia enemmän magnesiumia, fosforia, kuparia, sinkkiä ja mangaania.

Taulukko 1. Rehujen kivennäiskoostumus (g/kg KA) kasvustonäytteissä sadonkorjuuhetkellä.

\begin{tabular}{lrrrrrrrrrrr} 
& K & $\mathrm{Ca}$ & $\mathrm{Mg}$ & $\mathrm{P}$ & $\mathrm{Na}$ & $\mathrm{Fe}$ & $\mathrm{Cu}$ & $\mathrm{Zn}$ & $\mathrm{Mn}$ & $\begin{array}{r}\mathrm{K} / \\
(\mathrm{Ca}+\mathrm{Mg})\end{array}$ & $\mathrm{Ca} / \mathrm{P}$ \\
\hline NSR & 33,9 & 5,63 & 2,02 & 3,66 & 0,33 & 86,2 & 9,5 & 26,9 & 26,9 & 1,93 & 1,54 \\
Vehnä & 19,9 & 1,70 & 1,13 & 2,93 & 0,29 & 5,4 & 4,9 & 23,2 & 14,6 & 2,85 & 0,58 \\
Virna & 26,7 & 11,40 & 2,55 & 3,75 & 0,51 & 23,7 & 8,5 & 24,9 & 9,8 & 0,87 & 3,04 \\
Vehnän tähkät & 9,6 & 0,73 & 1,59 & 4,37 & 0,19 & 13,4 & 4,7 & 36,8 & 34,1 & 1,46 & 0,17 \\
Vehnän korret & 23,8 & 2,11 & 0,81 & 2,35 & 0,33 & 61,5 & 4,0 & 18,8 & 14,3 & 3,47 & 0,90 \\
\hline
\end{tabular}

VVSR:n KA-pitoisuus oli keskimäärin 356 g/kg, pH 4,74, D-arvo 59,9 \% ja syönti-indeksi 87,4. KAkilo sisälsi ND-kuitua 517 g, 0,81 RY, 152 g raakavalkuaista, 79 g OIV ja 43 g PVT. NSR:n vastaavat arvot olivat 387 g/kg, 5,36, 66,9 \%, 98,5, 508 g, 0,92 RY, 143 g, 81 g ja 5 g. Tärkkelystä VVSR sisälsi keskimäärin 62,9 g/kg KA. Rehut säilyivät paaleissa hyvin ja pilaantumisen johdosta poistettiin avattujen paalien pinnasta rehua vain hieman kokeen alussa. Rehujen säilönnällinen laatu oli hyvä, voihappoa NSR sisälsi kuitenkin 2,8 g/kg KA. Väkirehu vähensi hiehojen karkearehun syöntiä huomattavasti (Taulukko 2). Kokonaiskuiva-aineen syönti oli koko koekaudelle laskettuna keskimäärin 5,8 kg 
(SD 0,49). Energian saanti muodostui väkirehulisällä suuremmaksi kuin pelkällä karkearehuruokinnalla (P<0,01, 5,3 vs. 4,7 RY). Raakavalkuaista hiehot söivät päivässä keskimäärin 817 g (SD 69,7). Väkirehulisä lisäsi puolestaan OIV:n päivittäistä saantia keskimäärin 55 g $(\mathrm{P}<0,01)$.

Taulukko 2. Rehujen syönti, energian, raakavalkuaisen, ND-kuidun ja ohutsuolesta imeytyvien aminohappojen (OIV) saanti.

\begin{tabular}{|c|c|c|c|c|c|c|c|c|}
\hline \multirow{2}{*}{$\begin{array}{l}\text { Karkearehu (K) } \\
\text { Väkirehu (V) }\end{array}$} & \multicolumn{2}{|c|}{ NSR } & \multicolumn{2}{|c|}{ VVSR } & \multirow[t]{2}{*}{ SEM $^{1}$} & \multicolumn{3}{|c|}{ Merkitsevyys $^{2}$} \\
\hline & + & - & + & - & & $\mathrm{K}$ & $\mathrm{V}$ & $\mathrm{K} * \mathrm{~V}$ \\
\hline \multicolumn{9}{|l|}{ Kuiva-ainetta, kg } \\
\hline Karkearehu & 4,22 & 5,57 & 4,35 & 5,38 & 0,223 & & $* * *$ & \\
\hline Kaura & 1,56 & & 1,51 & & 0,035 & & & \\
\hline Kivennäinen & 0,141 & 0,141 & 0,141 & 0,141 & & & & \\
\hline Yhteensä & 5,92 & 5,70 & 6,00 & 5,51 & 0,216 & & & \\
\hline Orgaanista ainetta, kg & 5,38 & 5,08 & 5,53 & 5,01 & 0,197 & & 0 & \\
\hline RY & 5,49 & 5,06 & 5,14 & 4,36 & 0,181 & 0 & $* *$ & \\
\hline Raakavalkuainen, g & 819 & 798 & 853 & 813 & 32,6 & & & \\
\hline NDF, g & 2569 & 2861 & 2662 & 2792 & 112,7 & & 0 & \\
\hline OIV,g & 489 & 447 & 490 & 423 & 17,2 & & $* *$ & \\
\hline PVT, g & -3 & 35 & 156 & 234 & 8,7 & $* * *$ & $* * *$ & $*$ \\
\hline
\end{tabular}

Dieetin väkirehulisä lyhensi hiehojen kasvatuskautta kuudella viikolla ( $<<0,01$, Taulukko 3). Tavoiteteuraspaino $180 \mathrm{~kg}$ saavutettiin lukuun ottamatta ilman väkirehulisää olleita VVSR-hiehoja, joilla tavoitteesta jäätiin keskimäärin 8 kg. Kahden kilon väkirehulisällä hiehot olivat keskimääriin 76 päivää, kilon väkirehulisällä 60 päivää. Nurmisäilörehulla hiehojen päiväkasvu oli keskimäärin 112 g parempaa kuin seossäilörehulla $(\mathrm{P}<0,01)$, väkirehu puolestaan tehosti hiehojen päiväkasvua $224 \mathrm{~g}(\mathrm{P}<0,001)$ ilman väkirehua olleisiin hiehoihin verrattuna. Hiehojen teurasprosentti oli keskimäärin 49,7 (SD 1,47) ja lihakkuus 5,1 (SD 0,31). NSR-hiehot rasvoittuivat merkitsevästi enemmän kuin VVSR-hiehot $(\mathrm{P}<0,01,3,9$ vs. 3,0). Lisäkasvukiloon NSR-hiehot käyttivät rehun KA:tta vähemmän kuin VVSRhiehot ( $\mathrm{P}<0,01,7,7$ vs. 9,2 kg). Väkirehulisä paransi rehun muuntosuhdetta $(\mathrm{P}<0,001,7,2$ vs. 9,7 kg).

Taulukko 3. Hiehojen kasvu, teurastulokset ja rehun muuntosuhde.

\begin{tabular}{|c|c|c|c|c|c|c|c|c|}
\hline \multirow{2}{*}{$\begin{array}{l}\text { Karkearehu (K) } \\
\text { Väkirehu (V) }\end{array}$} & \multicolumn{2}{|c|}{ NSR } & \multicolumn{2}{|c|}{ VVSR } & \multirow[t]{2}{*}{ SEM $^{1}$} & \multicolumn{3}{|c|}{ Merkitsevyys $^{2}$} \\
\hline & + & - & + & - & & $\mathrm{K}$ & $\mathrm{V}$ & $\mathrm{K} * \mathrm{~V}$ \\
\hline Kokeen alussa, kg & 253 & 253 & 253 & 254 & 6,9 & & & \\
\hline Kokeen lopussa, kg & 365 & 363 & 363 & 351 & 3,3 & o & o & \\
\hline Teuraspaino, kg & 184,8 & 179,5 & 180,2 & 171,8 & 2,69 & $*$ & $*$ & \\
\hline Kuntoluokka, alussa & 2,61 & 2,81 & 2,64 & 2,71 & 0,044 & & $* *$ & \\
\hline Kuntoluokka, lopussa & 3,13 & 2,98 & 3,03 & 2,93 & 0,047 & & $*$ & \\
\hline Ikä kokeen alussa, pv & 215 & 215 & 210 & 216 & 3,4 & & & \\
\hline Kokeen kesto, pv & 130 & 164 & 140 & 193 & 11,8 & & $* *$ & \\
\hline Väkirehua, pv & 131 & - & 141 & - & 9,8 & & & \\
\hline Kasvu, g/pv & 852 & 679 & 790 & 515 & 30,9 & $* *$ & $* * *$ & \\
\hline Nettokasvu $^{3}$ & 443 & 324 & 381 & 241 & 17,8 & $* * *$ & $* * *$ & \\
\hline Teuras-\% & 50,7 & 49,4 & 49,6 & 49,0 & 0,67 & & & \\
\hline Lihakkuus ${ }^{4}$ & 5,0 & 5,2 & 5,2 & 5,0 & 0,14 & & & \\
\hline Rasvaisuus $^{5}$ & 4,0 & 3,8 & 3,1 & 3,0 & 0,26 & $* *$ & & \\
\hline \multicolumn{9}{|l|}{ Rehun muuntosuhde } \\
\hline KA kg/lisäkasvu-kg & 6,92 & 8,42 & 7,57 & 10,93 & 0,502 & $* *$ & $* * *$ & 0 \\
\hline KA kg/nettokasvu-kg & 13,30 & 17,63 & 15,73 & 23,66 & 1,205 & $* *$ & $* * *$ & \\
\hline RY/lisäkasvu-kg & 6,43 & 7,49 & 6,49 & 8,63 & 0,413 & & $* *$ & \\
\hline RY/nettokasvu-kg & 12,36 & 15,68 & 13,49 & 18,70 & 0,978 & $*$ & $* * *$ & \\
\hline
\end{tabular}


Väkirehua saaneiden hiehojen ulkofileen maku arvioitiin aistinvaraisessa arvostelussa suuntaa antavasti paremmaksi kuin pelkällä karkearehulla kasvatettujen hiehojen ulkofileen maku $(\mathrm{P}<0,10,5,0$ vs. 4,5, Taulukko 4.). Väkirehulisä paransi VVSR-hiehojen lihan mureutta, mutta NSR-ruokinnalla vaikutus oli lievästi päinvastainen. Vastus lihapalaa leikatessa oli pienempi, kun hiehot saivat väkirehua $(\mathrm{P}<0,05,10,4$ vs. 15,8). Ulkofileen loppu-pH oli keskimäärin 5,6 (SD 0,12) ja kaikkien ruhojen ulkofileen loppu-pH oli alle 6,00 eli tervalihaprosentti oli 0.

\section{Taulukko 4. Ruokinnan vaikutus hiehojen ulkofileen aistinvaraiseen laatuun.}

\begin{tabular}{|c|c|c|c|c|c|c|c|c|}
\hline \multirow{2}{*}{$\begin{array}{l}\text { Karkearehu (K) } \\
\text { Väkirehu (V) }\end{array}$} & \multicolumn{2}{|c|}{ NSR } & \multicolumn{2}{|c|}{ VVSR } & \multirow[t]{2}{*}{ SEM $^{1}$} & \multicolumn{3}{|c|}{ Merkitsevyys $^{2}$} \\
\hline & + & - & + & - & & $\mathrm{K}$ & $\mathrm{V}$ & $\mathrm{K} * \mathrm{~V}$ \\
\hline \multicolumn{9}{|c|}{ Aistinvarainen arvio $^{3}$} \\
\hline Mureus & 4,9 & 5,0 & 4,9 & 4,1 & 0,21 & $*$ & o & * \\
\hline Mehukkuus & 5,0 & 5,2 & 5,2 & 5,0 & 0,16 & & & \\
\hline Maku & 4,7 & 4,6 & 5,3 & 4,4 & 0,25 & & o & \\
\hline Konsistenssi ${ }^{4}$ & 10,0 & 14,4 & 10,8 & 17,3 & 2,17 & & * & \\
\hline Ulkofileen $\mathrm{pH}_{24}$ & 5,60 & 5,60 & 5,60 & 5,68 & 0,055 & & & \\
\hline
\end{tabular}

${ }^{1}$ Keskiarvon keskivirhe.

${ }^{2}$ o $\mathrm{P}<0,10 ; * \mathrm{P}<0,05 ; * * \mathrm{P}<0,01$; *** $\mathrm{P}<0,001$.

${ }^{3}$ Aistinvarainen arvio: asteikko 1-7, esim. $7=$ =erittäin murea.....1=erittäin sitkeä.

${ }^{4}$ Vastus lihapalaa leikatessa.

\section{Johtopäätökset}

Vehnä-virnaseossäilörehu osoittautui kokeessa tuotantovaikutuksiltaan heinän odelmasta tehtyä nurmisäilörehua heikommaksi karkearehuksi. Suurin syy tähän lienee ollut seossäilörehun huono sulavuus eli alhainen D-arvo, joka oli 7 \%-yksikköä alhaisempi kuin nurmisäilörehun. Hiehojen päiväkasvu kokoviljaseossäilörehulla ilman väkirehua jäi heikoksi ollen keskimäärin vain 515 g. Dieetin väkirehu tehosti hiehojen kasvua huomattavasti. Ruokintojen vaikutus lihan syöntilaatuun oli marginaalinen. Virnan siemenmäärän lisääminen kylvöseokseen tai muu korjuuaika olisi mahdollisesti nostanut seosrehun sulavuutta.

Kiitokset MTT:n emolehmänavetan, Kiteen koulutilan navetan ja opetusteurastamon henkilökunnalle sujuvasta ja huolellisesta yhteistyöstä kokeen toteutuksessa.

\section{Kirjallisuus}

Friedel, K. 1990. Die Schätzung des energetischen Futterwertes von Grobfutter mit Hilfe einer Cellulasemethode.[The estimation of the energetic feeding value of roughages by means of a cellulase method]. Wissenschaftliche Zeitung Universitet Rostock, N-Reihe 39, 78-86.

Joki-Tokola, E., Huuskonen, A., Huttu, S. \& Kiljala, J. 2002. Rehuvirna lihanautojen kokoviljasäilörehuruokinnassa. In: Maataloustieteen päivät 9.-10.1.2002. Kotieläintiede. MKL:n julkaisuja no 977. p. 196-199.

Lehto, E. \& Joki-Tokola, E. 1999a. Kauran ja rehuvirnan seoskasvuston korjuu säilörehuksi. Koetoiminta ja Käytäntö 22.6.1999.

Lehto, E. \& Joki-Tokola, E. 1999b. Virna sopii hyvin rehukasviksi. Koetoiminta ja Käytäntö 21.12.1999. Lowman, B.G., Scott, N.A. \& Somerville, S.H. 1976. Condition scoring of cattle. The East of Scotland College of Agriculture, Bulletin No.6.

Manninen, M. \& Ojajärvi, P. 2000. Rypsitäydennyksen vaikutus kokoviljasäilörehuruokinnalla hereford- ja ayrshire-hiehojen kasvuun sekä ruhon ja lihan laatuun. Kotieläintieteen päivät 2000. MKL:n julkaisuja no 952. p. 169-172.

Manninen, M., Ojajärvi, P. \& Suvitie, M. 2004. Kaura-rehuvirnasäilörehu teurashiehojen ruokinnassa. In: Maataloustieteen Päivät 2004, 12-13.1.2004 Viikki, Helsinki. Suomen Maataloustieteellisen Seuran tiedote no 19. http://www.agronet.fi/maataloustieteellinenseura/julkaisut/posterit04/kr11.pdf

Manninen, M., Virkajärvi, P., Ojajärvi, P., Jauhiainen, L. \& Suvitie, M. 2002. Toisen laidunkauden vaikutus teuraaksi kasvatettavien hf-hiehojen kasvuun sekä ruhon ja lihan laatuun. In: Maataloustieteen päivät 9.10.1.2002. Kotieläintiede. MKL:n julkaisuja no 977. p. 188-191.

McCleary, B.V., Solah, V. \& Gibson, T.S. 1994. Quantitative measurement of total starch in cereal flours and products. J. Cereal Sci. 20: 51-58.

Rinne, M., Harinen, T., Asikainen, U., Huhta, H. \& Aspila, P. 1998. Ruokinnan voimakkuuden vaikutus teurashiehojen kasvuun. Kotieläintieteen päivät 1998. MKL:n julkaisuja no 924. p. 293-296. 
Rinne, M. \& Ojajärvi, P. 1998. Ohra ja rypsirouhe rajoitetusti säilörehua saaneiden teurashiehojen väkirehuna. Kotieläintieteen päivät 1998. MKL:n julkaisuja no 924. p. 297-302.

SAS. 1999. SAS/STAT User's Guide, Version 8, Cary, NC: SAS Institute Inc. 3809 p.

Tuori, M., Kaustell, K., Valaja, J., Aimonen, E., Saarisalo, E. \& Huhtanen, P. 2002. Rehutaulukot ja ruokintasuositukset. Helsinki. 88 p.

Van Soest, P.J., Robertson, J.B. \& Lewis, B.A. 1991. Methods for dietary fiber, neutral detergent fiber and nonstarch polysaccharides in relation to animal nutrition. J. Dairy Sci. 74: 3583-3597. 